\title{
A EXPLORAÇÃO NOS CONTRATOS COMO DILEMA SOCIAL
}

\author{
Leandro Martins Zanitelli
}

\section{RESUMO}

O artigo procura caracterizar as ocorrências de exploração contratual como situações de dilema social, nas quais a atuação autointeressada e racional dos indivíduos leva a um resultado indesejável. Destacamse três pontos da teoria dos dilemas sociais: a) o da identificação com o grupo; b) o da lógica da adequabilidade; e c) o dos sistemas sancionadores. Entre as conclusões, o trabalho salienta a dificuldade de alcançar-se a cooperação (que se traduziria, no caso examinado, pela recusa à exploração) por outros meios que não incentivos ou "soluções estruturais" mediante as quais se alinhem os interesses dos agentes aos da coletividade.

Palavras-chave: Contratos. Exploração. Dilemas sociais.

* Doutor em Direito pela Universidade Federal do Rio Grande do Sul (UFRGS), com estágio de pós-doutorado na Universidade de Hamburgo, Alemanha; professor e coordenador do Programa de Pós-Graduação Stricto Sensu; mestrado acadêmico em Direito pelo Centro Universitário Ritter dos Reis (UniRitter); professor do Curso de Graduação em Direito do UniRitter. 


\begin{abstract}
Contractual exploitation in competitive markets (for example, the exploitation of workers and consumers by firms) is presented as a case of social dilemma, which is defined as a circumstance under which self-interested and rational behavior by individual agents leads to undesirable consequences for all. The paper draws on three topics of the theory on social dilemmas: a) group identification; b) logic of appropriateness and c) sanctioning systems. Among its findings, the article stresses the difficulty of obtaining cooperation by means other than incentives or "structural solutions" through which individual and collective interests are reconciled.
\end{abstract}

Keywords: Contracts. Exploitation. Social dilemas.

\title{
INTRODUÇÃO
}

Com o advento do Código de Defesa do Consumidor (Lei $\mathrm{n}^{\circ}$ 8.078/1990) e a sua vedação a cláusulas abusivas (v., em especial, o art. 51) seguida, alguns anos depois, pela inclusão da lesão entre as causas de anulabilidade no novo Código Civil (art. 157), pouca dúvida pode haver de que a legislação brasileira tem como um de seus escopos o combate à exploração nos contratos. A aversão a contratos "leoninos", que oferecem a uma das partes vantagem tida como exagerada, é também proclamada pela doutrina, na qual se fala de um princípio da justiça contratual ${ }^{1}$ ou do equilíbrio econômico ${ }^{2}$ nos contratos, e manifestada pela jurisprudência mediante a aplicação das disposições legais já referidas e também das "cláusulas gerais" da função social do contrato $^{3}$ (Código Civil, art. 421) e da boa-fé ${ }^{4}$ (Código Civil, art. 422).

Alan Wertheimer alude, contudo, à dificuldade para conceber-se a exploração quando aquele a quem se acusa de explorar a outra parte se encontra submetido à concorrência:

Eu não nego que a exploração possa ocorrer em um mercado perfeitamente competitivo [...]. Não obstante, quando dizemos que A obtém injusta vantagem de B, nós 
usualmente pressupomos que A poderia ter escolhido não obter injusta vantagem de B, isto é, que a transação por eles realizada poderia ter ocorrido sob condições mais equânimes. Pois isso é precisamente o que, em geral, não pode ocorrer em um mercado perfeitamente competitivo [...]. Se um empregador paga a seus empregados demasiado bem, ele será desbancado por competidores capazes de estabelecer preços menores porque pagam menos aos seus empregados. ${ }^{5}$

O exemplo diz respeito às relações de trabalho, mas o argumento também se aplica às demais relações contratuais de que é parte o empresário sujeito à competição, incluindo as relações de consumo. O fornecedor que ofereça um contrato de adesão com condições mais favoráveis aos consumidores do que as de seus concorrentes arriscase a ser superado pelos preços mais baixos desses últimos, a não ser, é claro, que os consumidores estejam dispostos a pagar mais caro por um contrato com cláusulas mais vantajosas para si.

Embora a aparente contradição, a observação de Wertheimer sobre mercados competitivos pode se coadunar com o propósito do atual Direito brasileiro de combater a exploração inclusive nesses mercados, contanto que se entenda que a preocupação do primeiro é com a qualidade moral da conduta, de quem se favorece, enquanto que a repressão legal teria como base não necessariamente a imoralidade da referida conduta mas também o resultado, puro e simples, de determinados contratos. Poder-se-ia dizer, assim, que, mesmo que o ato pelo qual o empresário consegue vantagem sobre a outra parte de uma relação contratual (trabalhador, consumidor etc.) seja moralmente irrepreensível, já que, devido à concorrência, esse empresário não poderia se comportar de outra maneira, ${ }^{6}$ o resultado do ato em questão é socialmente indesejável e, por isso (e independentemente de considerar-se esse como um caso de exploração), deve ser prevenido. Mais ainda, é-se tentado a concluir que a irresistibilidade da exploração (ou qualquer outro nome que se dê à obtenção de vantagem) sob circunstâncias de competição faz com que a prevenção dessa exploração tenha que se esperar da lei, e não da boa vontade de quem quer seja. $\mathrm{O}$ argumento de Wertheimer e o Direito contratual 
brasileiro atual teriam, portanto, uma afinidade que a divergência das conclusões põe à sombra: a ideia do homo economicus presente no ponto de vista sobre a exploração defendido pelo primeiro é a mesma a sugerir que, diante da cobiça sem limites (e inexorável) dos agentes em mercados competitivos, a dureza da lei é, se não a única, no mínimo uma resposta adequada.

O objetivo do presente trabalho é reexaminar a questão do equilíbrio ou justiça nos contratos à luz da teoria dos dilemas sociais. Costuma-se considerar que há um dilema social sempre que a busca individual do maior ganho possível (o que se chama, no linguajar da teoria do dilema social, defecção, defection) conduz a um resultado inferior, tendo-se em vista o bem-estar de cada um, o que seria alcançado mediante um comportamento não egoísta (que se designa como cooperativo). ${ }^{7}$ Pode-se ilustrar a ideia com um exemplo do dia a dia: embora seja mais confortável para mim não recolher os dejetos dos meus animais de estimação, se todos se comportarem dessa maneira, o estado de coisas daí resultante (para mim e para os demais) será pior do que um no qual todos cooperem.

A ideia de aplicar a teoria dos dilemas sociais à exploração contratual tem como base certa similitude entre a estipulação do preço e das demais condições de um contrato sob condições de competição e aquilo que usualmente se considera (tal como o recolhimento das fezes do cão) um dilema social. Em ambos os casos, o comportamento egoísta leva a um resultado indesejável, embora (uma distinção a que se voltará adiante), nos dilemas sociais comuns, essa indesejabilidade seja aferida considerando-se o bem-estar dos agentes mesmos (no exemplo, a defecção universal acarreta um resultado que contraria o interesse dos próprios donos dos animais), o que não necessariamente acontece quando se trata da vantagem a extrair da outra parte em um contrato. Em ambos os casos, também, cada agente pode ser levado à defecção não só porque essa seja, independentemente do que os demais fizerem, a melhor alternativa (em linguagem de teoria dos jogos, a "estratégia dominante"), mas também pelo receio de que os demais não cooperem, já que aquele que é o único a cooperar é reduzido, sob tais circunstâncias, a uma espécie de "pior dos mundos" no qual se renuncia ao bem-estar imediato que o comportamento 
individual poderia proporcionar mas não se logra, ou se logra apenas minimamente, o resultado socialmente desejado. Isso corresponde, como lembra Wertheimer na passagem acima transcrita, à posição do contratante a quem a obtenção da máxima vantagem possível junto à contraparte é ditada, se não pela cobiça, ao menos pelo temor de que, em não o fazendo, acabe batido por seus competidores.

A justificativa para incorporar a teoria dos dilemas sociais à análise dos contratos e, em especial, à da exploração contratual reside na larga e diversificada experiência científica acumulada sob a primeira ao longo das últimas décadas. Alternativas de solução para dilemas sociais têm ocupado pesquisadores de áreas como a Psicologia, a Economia, a Sociologia e a Antropologia. À medida que a exploração contratual se assemelhe a um dilema social, os resultados dos estudos citados, muitos deles baseados em experimentos destinados a comparar a resposta dos agentes com diferentes versões de dilema, podem enriquecer a teoria jurídica contratual e servir de orientação a novas medidas legislativas. É de lamentar que, entre as inúmeras áreas do conhecimento das quais se nutre a teoria dos dilemas sociais, a do Direito às vezes não chegue sequer a ser lembrada, ${ }^{8}$ e isso não só pelas consequências para a ciência jurídica que daí decorrem, como pela contribuição que a pesquisa em Direito é capaz de oferecer à teoria em questão, a qual poderia, graças à mencionada contribuição, aperfeiçoar-se no que se refere ao potencial de normas jurídicas para a solução de dilemas sociais.

$\mathrm{O}$ artigo é dividido da seguinte maneira. Na primeira parte, tratarse-á da exploração nos contratos como dilema social, ressaltando-se não só as características da exploração que permitem examiná-la como dilema social, mas também a diferença entre a exploração e aquilo que mais comumente se reputa como dilema, bem como, ainda, as possíveis implicações dessa diferença no que diz respeito à aplicação da teoria dos dilemas sociais aos contratos. A segunda parte apresentará as principais ramificações da teoria dos dilemas sociais de maneira a estabelecer quais delas podem ter maior interesse para o que respeita à exploração nos contratos. Nela, procurar-se-á explicitar as razões desse interesse e, a partir daí, fazer sugestões para pesquisa futura. 


\section{CARACTERIZAÇÃO DA EXPLORAÇÃO NOS CONTRATOS COMO DILEMA SOCIAL}

Sobre os dilemas sociais, é comum ter-se como referência a definição de Dawes, ${ }^{9}$ segundo a qual, para que um dilema social se verifique, é preciso: a) que a conduta antissocial (isto é, defectiva) seja a que assegure a cada indivíduo o melhor resultado (também chamado de "remuneração" ou payoff) independentemente do que façam os demais; e b) que o resultado da conduta pró-social (cooperativa) de todos seja superior ao da conduta inversa, isto é, que a cooperação universal resulte em mais vantagem para cada indivíduo do que a defecção. Em uma síntese feliz e também frequentemente citada, Kollock observa que "[...] dilemas sociais são situações nas quais a racionalidade individual conduz à irracionalidade coletiva", ${ }^{10}$ já que a melhor alternativa para o indivíduo isolado é a que leva, quando universalmente escolhida, a um resultado indesejado por todos.

A representação mais célebre de um dilema social é a do dilema do prisioneiro. Nela, dois indivíduos suspeitos de um crime veem-se perante as seguintes alternativas: se apenas um deles confessar, restará livre, e ao outro caberá a pena máxima, cinco anos de prisão; caso nenhum dos dois confesse, ambos cumprirão pena de um ano; se os dois confessarem, sofrerão uma pena intermediária, de três anos. Tratase aí de uma situação caracterizável como dilema porque, para cada um dos prisioneiros, independentemente do que o outro faça, a melhor estratégia (estratégia dominante) é confessar. A confissão é melhor do que o silêncio para o prisioneiro $A$, se o prisioneiro $B$ confessar também ( $A$ cumprirá três anos, pena inferior à que receberia se fosse o único a silenciar) e melhor na hipótese contrária, isto é, em que $B$ silencie (nessa hipótese, $A$ estará livre e, portanto, melhor do que com a pena de um ano que sofreria caso, a exemplo de $B$, silenciasse). Como a situação de $B$ é análoga à de $A$, se cada prisioneiro escolher a melhor estratégia para si, ambos confessarão e terão de cumprir pena de três anos de prisão, uma pena maior (e um resultado inferior, considerando-se a preferência dos acusados pela liberdade) à que resultaria do silêncio de ambos. No dilema do prisioneiro, o silêncio corresponde, pois, à cooperação, e a confissão, à defecção. ${ }^{11}$ 
Para deixar mais clara a similitude entre a exploração contratual e dilemas sociais exemplificados pelo dilema do prisioneiro, considere-se um empresário $X$ para quem certa pessoa $Y$ esteja disposta a trabalhar por um salário ínfimo s0. Para simplificar, suponha-se que $X$ disponha de apenas duas alternativas, a saber, contratar $Y$ por $s 0$ ou contratá-lo por um salário maior, s1. Além de $X$, imagine-se ainda um ou mais empresários concorrentes que, como o primeiro, deparam-se com oferta de mão de obra barata e podem, também, a exemplo de $X$, aceitála pelo salário mínimo exigido $\mathrm{s} 0$ ou oferecer um pouco mais, s1. Como no dilema do prisioneiro, há para cada um desse empresários uma estratégia dominante, isto é, uma conduta que os deixará em melhor situação independentemente da conduta dos demais, a qual consiste em contratar o trabalhador por $\mathrm{s} 0$. Essa é a estratégia dominante para o empresário $X$ porque, se todos os demais pagarem $s 1$ a seus respectivos trabalhadores, $X$ estará em vantagem em relação a seus oponentes; se, ao contrário, o salário estipulado pelos demais for $\mathrm{s} 0$, pagar $\mathrm{s} 0$ também é a alternativa que permitirá a $X$ manter os preços de seus produtos no mesmo patamar dos concorrentes. ${ }^{12}$

Um outro exemplo, envolvendo desta vez empresários e consumidores: em um artigo publicado há alguns anos atrás, Hanson e Kysar argumentaram, com base em estudos sobre a racionalidade limitada de consumidores, que os comerciantes não apenas podem beneficiar-se das falhas decisórias de consumidores (por exemplo, o "viés otimista", que leva os consumidores a subestimar os riscos advindos dos bens que adquirem), como estariam forçados a fazê-lo, sob pena de serem superados por seus rivais. ${ }^{13}$ Por causa da racionalidade limitada, a competição entre fabricantes teria lugar, em outras palavras, não só quanto ao preço e qualidade dos produtos oferecidos, mas também quanto à habilidade para tirar proveito das falhas decisórias dos consumidores. Pode-se, então, admitindo o argumento de Hanson e Kysar, comparar novamente a situação do empresário X com a de um dilema social no qual se trate, agora, da exploração dos consumidores - por exemplo, um no qual $X$ se depare com a alternativa de incluir ou não nos contratos de adesão que celebra uma cláusula que o exima da responsabilidade por determinado risco que, não obstante a sua gravidade, é negligenciado pela maioria dos consumidores. Para $X$, 
assim como para os demais empresários, a estipulação de tal cláusula é a estratégia dominante, isto é, a que deixará $X$ em melhor situação quer os demais façam o mesmo (caso em que $X$ não arcará com custos de responsabilidade superiores aos dos demais), quer não (quando então $X$ ficará em vantagem em relação a seus competidores).

Se, de um lado, a exploração de trabalhadores e consumidores é a estratégia dominante para empresários em situações como a dos exemplos recém-expostos e, portanto, confere a essas situações a primeira das duas características atribuídas por Dawes ${ }_{,}^{14}$ o que pode, de outro, levantar dúvida sobre a sugestão de tratar a exploração nos contratos como dilema social é a segunda dessas características, isto é, a de que a recusa à cooperação, que se apresenta, a cada um dos agentes individualmente considerados, como a melhor alternativa, conduza a um resultado que seja, para esses agentes, inferior ao que adviria da cooperação de todos. Uma perfeita analogia requereria, quanto a isso, que o estado de coisas no qual todos os empresários contratam trabalhadores ao salário s1 e se abstême de tirar vantagem do otimismo exagerado dos consumidores seja preferível, não só para trabalhadores e consumidores, mas também para os empresários.

O quão importanteé a diferença entre um dilema social como o retratado pelo exemplo dos prisioneiros, no qual o resultado da cooperação universal é patentemente mais vantajoso para os agentes (menos anos de prisão), e o caso da exploração de trabalhadores e consumidores por empresários, no qual essa vantagem não se verifica? Uma primeira observação a fazer é que, mesmo afastada a hipótese do altruísmo, isto é, mesmo se admitindo que cada um dos envolvidos se ocupe unicamente com o próprio bem-estar, o resultado a esperar das escolhas individuais é, em uma e outra hipótese, rigorosamente o mesmo. Em outras palavras, o fato de a cooperação redundar em benefício de todos no que mais comumente se designa como dilema social não impede que, à falta de alguma solução "externa", a resposta de indivíduos autointeressados seja, também sob tais circunstâncias, a defecção.

Pondere-se, em segundo lugar, que parte do que se tem sugerido como solução para dilemas sociais leva a ver a diferença entre situações nas quais a cooperação atende a uma preferência egoísta dos indivíduos e aquelas nas quais o que resulta é algo simplesmente valioso ou socialmente desejável (considerando-se aí não mais apenas o bem-estar dos agentes) como bem menos relevante do que pode, ao início, parecer. Para ficar, 
por ora, com apenas um exemplo, refiram-se os estudos nos quais se apresentam "sentimentos morais" (moral sentiments) ${ }^{15}$ ou "orientações de valor social" (social value orientations) ${ }^{16}$ como meio de superação de dilemas sociais. $\mathrm{O}$ que esses estudos sugerem é que a cooperação, ao invés de depender exclusivamente de incentivos por meio dos quais a satisfação de indivíduos egoístas se alinhe ao socialmente desejável, é às vezes obtida espontaneamente, isto é, em circunstâncias nas quais a conduta pró-social parece ter-se de atribuir a motivações altruístas. Ora, se é crível que a solução para um dilema social reside, ocasionalmente, na simples disposição a cooperar de indivíduos cujo comportamento se percebe divergir, por isso mesmo, daquele atribuído ao homo economicus, por que então recusar-se, já de saída, a aplicação do modelo a casos nos quais se tenha de contar com o abandono do mais estrito egoísmo, ao invés de apenas para a cooperação em si, também para o fim que com ela se almeja? É, sem dúvida, contraditório incluir o altruísmo entre as possíveis soluções para o dilema social, como se faz por vezes na literatura, e, não obstante, insistir em tratar como dilema apenas o que seria reconhecido como tal por agentes egoístas.

Isso serve para justificar o interesse da pesquisa sobre dilemas sociais para a área dos contratose, em particular, para a exploração contratual, mas não, é claro, para negar que a peculiaridade das situações de exploração deva ser levada em conta quando se trate de estender-lhes as conclusões da pesquisa antes mencionada. Na parte seguinte do artigo, apresentarse-ão pontos da teoria do dilema social com potencial relevância para os contratos, sempre tendo em vista a referida peculiaridade e a necessidade de desenvolver as possibilidades de investigação aqui levantadas.

\section{A TEORIA DOS DILEMAS SOCIAIS: SÍNTESE DE PONTOS RELEVANTES}

Nesta parte, far-se-á uma análise das implicações para o que se refere à exploração nos contratos dos seguintes pontos da teoria dos dilemas sociais: a) identidade social ou de grupo; b) escolha racional versus "lógica da adequabilidade"; c) sistemas sancionadores. 


\section{IDENTIDADE SOCIAL OU DE GRUPO}

É comum fazer-se na literatura uma distinção entre soluções estruturais e individuais para dilemas sociais. ${ }^{17}$ As primeiras caracterizam-se por uma alteração de payoffs graças à qual a cooperação termina por se mostrar a melhor alternativa para indivíduos autointeressados. A solução estrutural é, pois, uma por via da qual o dilema social deixa de sê-lo, já que se coadunam, em virtude dela, os interesses do indivíduo e da coletividade. Um exemplo de solução como essa é o da sanção legal: uma vez estabelecido por lei um salário mínimo (e supondo-se uma punição rigorosa e altamente provável aos infratores), o pagamento desse salário, que corresponderia, de acordo com o sugerido acima, à cooperação, revela-se também o melhor a fazer para um empresário cuja única preocupação seja a de maximizar os próprios ganhos.

Soluções individuais são, em contrapartida, as que dizem respeito a determinantes motivacionais ou cognitivas do comportamento. Entre essas soluções está a identidade social ou de grupo (social ou group identity). A hipótese, corroborada por experimentos em laboratório, ${ }^{18}$ é que a identificação com um grupo faz aumentar o nível de cooperação sempre que se tratar de dilemas "internos" (ou intragrupo), isto é, de situações nas quais a cooperação (ou falta dela) é determinante para o bem-estar de outros membros do mesmo grupo.

A diferença entre o comportamento extra e intragrupo (esse último caracterizado pela maior cooperação) é explicada de duas maneiras. ${ }^{19}$ Primeiro, cogita-se que a identificação do agente com o grupo provoque, juntamente com a ênfase nos efeitos da conduta de cada um sobre o bem-estar dos demais, uma alteração motivacional em virtude da qual os agentes passam a ter em vista o bem-estar do grupo em lugar do seu ou, em outras palavras, pela qual o bem-estar de cada um passe a depender do bem-estar de todos. Essa hipótese explicativa é, portanto, a da "transformação de objetivo" (transformation goal), uma em que se postula a identificação como fator capaz de levar indivíduos com orientação egoísta a se conduzirem de maneira pró-social.

Outra possível explicação para a cooperação intragrupo tem como base a confiança. Parte-se, nesse caso, da ideia segundo a qual, em 
situações de dilema social em geral, muitos agentes com predisposição a cooperar deixariam de fazê-lo por temer a defecção dos demais, isto é, negar-se-iam a cooperar por antever a falta de reciprocidade. Tem-se constatado, no entanto, uma tendência a atribuir aos demais membros de um mesmo grupo certas qualidades positivas, inclusive a confiabilidade. Assim, a identificação com o grupo, e o juízo favorável que ela traz consigo, contribuiria para criar entre os agentes a expectativa de reciprocidade, um estímulo a que aqueles com propensão a cooperar de fato o façam. Essa hipótese é designada como a de "amplificação do objetivo" (amplification goal), uma de acordo com a qual a identidade de grupo não se mostra apta a reorientar o comportamento (indivíduos predispostos a atuar egoisticamente continuariam conduzindo-se como tais), mas tão somente a induzir a busca do bem comum pelos que já se encontram a tanto inclinados.

Mormente quando a primeira das duas hipóteses de explicação, a da transformação do objetivo, for a verdadeira, a solução da identidade de grupo esbarra, no que concerne à exploração contratual, no fato de ter-se em tal caso um dilema no qual, muito embora se tenha em vista a conduta de indivíduos que, apesar de competidores, se consideram frequentemente pertencentes ao mesmo grupo, o dos empresários, o resultado almejado é um que releva eminentemente, como observado na parte anterior, não para esses indivíduos, mas para outros que ocupam o polo inverso da relação contratual e que são muito comumente representados como participantes de um grupo distinto e antagônico - seja, para ficar com os exemplos principais, o dos trabalhadores, seja o dos consumidores. Quando se cogita, pois, que a identificação com o grupo tenha o condão de fazer substituir motivações egoístas por outras mais favoráveis à promoção do bem-estar do grupo, a particularidade de tratar-se, nas situações de exploração, de um dilema no qual os benefícios da cooperação se estendem a outros que não os seus próprios agentes acaba mostrando relevância.

No que se refere, por outro lado, à hipótese da amplificação do objetivo, é preciso considerar que a expectativa de reciprocidade pode depender do tamanho do grupo, revelando-se, tendencialmente, tanto menor aquela quanto maior esse último. Essa suposição se coaduna com 
experimentos nos quais o tamanho do grupo foi um dos determinantes do nível de cooperação, embora também se cogite que o menor nível de cooperação em grupos maiores seja determinado não pelo tamanho do grupo em si, mas pela redução do impacto (ou eficácia) da contribuição de cada indivíduo sob tais circunstâncias. ${ }^{20}$ Assim, admitindo-se a hipótese da amplificação do objetivo, a cooperação, entendida como recusa à exploração, faz-se menos provável à medida que aumenta o número de empresários sujeitos à concorrência. Além disso, mesmo que esse último número se mostre reduzido, há que se ressaltar que a identificação com o grupo, e a confiança, que essa identificação traz consigo, na boa vontade dos demais componentes somente serviria de antídoto à exploração quando acompanhada ou da junção das duas partes da relação contratual sob o mesmo grupo (o que não acontece quando se opõe, por exemplo, ao grupo dos empresários o dos trabalhadores) ou de algum outro fator de estímulo por meio do qual indivíduos aptos a explorar deixem de atuar em seu exclusivo interesse.

\section{ESCOLHA RACIONAL VERSUS "LÓGICA DA ADEQUABILIDADE"}

Weber, Kopelman e Messick $^{21}$ propõem dividir a análise do comportamento em dilemas sociais em duas abordagens distintas. Uma, que eles reputam predominante, é a teoria da escolha racional (rational choice); outra, contraposta à primeira, é a abordagem representada pela "lógica da adequabilidade" (logic of appropriateness) descrita por March. ${ }^{22}$

Característica da teoria da escolha racional é a suposição de que os indivíduos decidem de acordo com as consequências das diferentes alternativas (daí falar-se também, nesse caso, em "lógica da consequência" $)^{23}$ com que se deparam. Além disso, postula-se que a alternativa escolhida seja a que proporcione ao agente a maior utilidade (teoria da utilidade esperada), ao que se acrescenta a presunção de que a utilidade de cada um seja exclusivamente determinada pelo próprio bem-estar (e para a qual seja irrelevante, portanto, o bem- 
estar de outros, com exceção, talvez, de familiares). Trata-se, aí, em síntese, do modus operandi comumente representado pela expressão homo economicus.

A lógica da adequabilidade diferencia-se da escolha racional ou da lógica da consequência, em primeiro lugar, porque descreve o processo de tomada de decisão como processo sujeito a regras. Segundo March, o processo decisório pode ser descrito como resultado da seleção de uma regra a seguir, regra essa que seria definida a partir da resposta a três questões: a questão do reconhecimento ("que espécie de situação é esta?"), a da identidade ("que espécie de indivíduo sou eu") e, finalmente, a da regra ("que espécie de regra um indivíduo como eu segue em uma situação como esta?") ${ }^{24}$

Como a obediência a regras é, geralmente, tarefa menos árdua do que a de ponderar as diversas consequências, mais e menos remotas, de todas as decisões possíveis, a lógica da adequabilidade coadunase, mais do que a sua rival, com os limites da racionalidade humana e com a simplificação decisória que esses limites impõem. Além disso, acredita-se que a decisão caracterizada pela sujeição a uma regra possa dar-se de maneira mais irrefletida quando comparada com a decisão consequencialista. ${ }^{25}$

A distinção entre lógica da adequabilidade e lógica da consequência é importante porque, à medida que o comportamento dos agentes corresponda mais fielmente à primeira do que à segunda, deixa de valer o pressuposto em virtude do qual situações de dilema social inevitavelmente redundariam em defecção universal, um resultado no qual a irracionalidade coletiva se manifestaria em sequência à racionalidade individual. A defecção, observe-se, é tida como estratégia dominante em dilemas como o do prisioneiro porque proporciona aos indivíduos um payoff superior ao da cooperação. Se, no entanto, o agente substitui a ponderação de prós e contras pela obediência a uma regra que considere adequada para si, a decisão de não cooperar deixa de ser inexorável.

Admitindo-se que o processo decisório obedeça, por vezes, à lógica da adequabilidade em substituição à lógica da consequência, a solução para situações de dilema passa a depender, primeiro, de que essa substituição de fato se verifique e, segundo, da regra que, em tal 
caso, o agente venha a seguir. Em relação ao primeiro ponto, o que interessa, do ponto de vista de uma ciência disposta a colaborar para a solução de dilemas reais, é estabelecer sob quais condições o emprego da lógica da adequabilidade se faz mais provável. A esse respeito, Weber, Kopelman e Messick enumeram três condições favoráveis a uma lógica de consequência e, portanto, pouco propícias à substituição dessa lógica pela da adequabilidade: a) quando o ambiente decisório é menos social; b) quando o contexto torna saliente a "estrutura econômica" (economic strutcture) da decisão a tomar; e c) quando o contexto convida a uma decisão mais calculada. ${ }^{26}$

Quanto à primeira das três condições, a ideia de quea "socialidade" do ambiente decisório facilita o abandono da lógica de consequência é alicerçada por experimentos nos quais se tem verificado que a comunicação entre os participantes resulta em maiores níveis de cooperação. Em outras palavras, mesmo quando postos em situação de dilema (na qual se insista, a defecção é a estratégia dominante), agentes com a chance de comunicarem-se uns com os outros não só acabam cooperando em alguma medida, como o fazem mais do que em experimentos nos quais a decisão é tomada isoladamente. ${ }^{27} \mathrm{~A}$ fim de explicar esse resultado, aventa-se ora que a comunicação promova a identificação com o grupo, ora que ela permita aos envolvidos alcançar um acordo ou compromisso (commitment) sobre a maneira de se comportarem. ${ }^{28}$ Note-se, entretanto, não haver, nos experimentos que se menciona, uma sanção para a violação do acordo, já que a existência de tal sanção equivaleria a uma alteração de payoffs e, por conseguinte, a uma possível desaparição do dilema. Assim, se o acordo propiciado pela comunicação aumenta a cooperação, é porque facilita o abandono do cálculo de consequências em favor da decisão conforme uma regra (no caso, a regra segundo a qual acordos devem ser cumpridos) característica da lógica da adequabilidade. ${ }^{29}$

Outra hipótese que, uma vez confirmada, corroboraria a sugestão de Weber, Kopelman e Messick acerca da influência das circunstâncias (que podem ser mais ou menos "sociais") sobre a tomada de decisão é a de que a comunicação (e outros fatores pelos quais se saliente o valor social do comportamento de cada um) contribua para a eficácia ou "ativação" de normas sociais em geral (e não apenas, pois, da norma 
pela qual se requeira o respeito a acordos realizados). Com relação às normas sociais, entendidas como normas não legais aceitas ${ }^{30}$ por determinado grupo, é de se observar que elas tanto podem interessar a uma análise na qual não se suponha a racionalidade egoísta dos agentes (ou, como se tem chamado nos últimos parágrafos, de lógica da consequência $)^{31}$ como a uma em que essa mesma suposição seja posta de lado. No primeiro caso, a norma social importa pelas sanções "informais" (como a censura ou o ostracismo) que sua violação é capaz de atrair. Essas sanções, quando fazem parte do payoff de uma conduta defectiva, podem ser graves o suficiente para transformar a cooperação na melhor escolha, não só do ponto de vista coletivo, mas também individual. No segundo caso, em contrapartida, a norma social é vista como meio de promover a cooperação independentemente das sanções a que o agente infrator se sujeite ou mesmo que, considerandose tão somente as consequências de cada uma das decisões possíveis, a gravidade da sanção pela inobservância da norma não baste para tornar a decisão de cooperar a mais vantajosa individualmente falando. ${ }^{32}$ Nessa última hipótese, tanto se pode aventar uma internalização da norma social graças à qual se encontre o agente intrinsicamente motivado a cumpri-la como postular uma obediência pouco refletida, muito mais amparada em "pistas" situacionais cruciais para uma lógica da adequabilidade do que em um juízo moral.

Tenha-se a atenção agora para a segunda das três condições elencadas por Weber, Kopelman e Messick, a que se refere à "estrutura econômica" da decisão a tomar. ${ }^{33}$ Note-se que os autores não se referem com isso a características da decisão em si, mas sim ao modo como essas características se apresentam aos agentes. Uma vez que esse modo de apresentação saliente certas características e não outras, haveria uma tendência, essa é a hipótese, a uma resposta baseada na lógica da consequência (isto é, a uma atuação racional, autointeressada) ou, inversamente, ao emprego da lógica da adequabilidade.

A ideia de que o modo como as alternativas são apresentadas ao agente influencie, independentemente dos prós e dos contras de cada uma dessas alternativas, a decisão é oriunda da pesquisa em Psicologia acerca dos "quadros" (frames) decisórios. Como quadro decisório, entende-se o modo como uma decisão é concebida pelo 
agente. Tal maneira de conceber, que se sujeita a fatores como normas (internalizadas) e hábitos, pode depender também do modo (externo) como a decisão é formulada. ${ }^{34}$ No estudo pioneiro de Tversky e Kahneman, ${ }^{35}$ percebeu-se, por exemplo, que uma das soluções para um problema fictício, uma doença asiática que ameaçava matar 600 pessoas, provocava reações diferentes, dependendo do modo como era formulada. Em um primeiro caso, propunha-se um plano de ação A graças ao qual 200 das potenciais vítimas seriam salvas, o que obteve a preferência de $72 \%$ dos respondentes (contra um outro plano B, pelo qual se teria uma chance em três de salvar todos e duas em três de não salvar ninguém). Para outro grupo, o mesmo plano A era apresentado como um pelo qual 400 das 600 pessoas ameaçadas morreriam, tendo então obtido a preferência de apenas $22 \%$ dos respondentes (contra uma alternativa equivalente à do primeiro caso).

Uma das possíveis implicações para situações de dilema social da hipótese geral dos quadros decisórios é, pois, a de que o nível de cooperação varie, em tais situações, de acordo com o modo como as alternativas são apresentadas. Quais são, no entanto, os modos de apresentação que, ao salientar as "propriedades econômicas" da escolha com que os agentes se deparam, torna-los-iam mais propícios a decidir egoisticamente? Não havendo espaço aqui para referir mais do que alguns poucos estudos a respeito, limitar-se-á a exposição àquilo que pode ser mais relevante para o tema da exploração nos contratos. ${ }^{36}$

Pillutla e Chen compararam o nível de cooperação, traduzido pela contribuição a um fundo comum, de grupos de estudantes que, no papel de representantes de uma fábrica, foram chamados ora a realizar um investimento conjunto, ora a colaborar para uma celebração. Embora os payoffs fossem rigorosamente os mesmos, os autores testaram a hipótese de que a primeira das decisões (a decisão de investimento), por apresentar-se como decisão "econômica", revelaria um média de contribuições inferior à da segunda (a decisão "não econômica), o que acabou por se verificar. ${ }^{37}$

Batson e Moran constataram, em um experimento com o dilema do prisioneiro, que o nome ou "rótulo" (label) dado à atividade alterava a conduta dos participantes. Para um dos grupos, designou-se a situação de dilema como de "intercâmbio social" (social exchange), enquanto 
para o outro uma situação formalmente idêntica foi apresentada como uma transação comercial (business transaction). O resultado foi um nível de cooperação maior no primeiro caso. ${ }^{38}$

Muito sugestivo foi, ainda, o resultado conseguido por van Dijk e Wilke em um estudo acerca do efeito de direitos de propriedade sobre o quadro decisório. Nele, usou-se uma versão do dilema do recurso (resource dilemma), também denominado dilema dos comuns (commons dilemma), uma espécie de dilema social no qual há uma certa quantidade de recursos dos quais os indivíduos podem apropriarse. Essas situações se apresentam como dilemas ao postular-se que o aproveitamento dos recursos é individualmente vantajoso, mas coletivamente nocivo (porque leva, por exemplo, ao esgotamento), o que se forjava, no trabalho citado, com a regra segundo a qual toda a quantia em dinheiro da qual os participantes deixassem de se apropriar individualmente seria multiplicada por dois e igualmente dividida entre todos. Compararam-se, então, os resultados de grupos provocados a decidir sob condições materialmente iguais, mas com diferenças de formulação no que respeita ao regime de propriedade. Assim, enquanto para um dos grupos o montante dos recursos a explorar dizia-se sujeito à propriedade coletiva, para outro esse mesmo montante declarava-se constituído por cotas individuais. Sem nenhuma distinção entre os payoffs, o que se observou foi que a apresentação do caso como um dilema de propriedade coletiva (primeiro caso) redundou em índices de cooperação (correspondentes ao percentual dos recursos deixado no fundo comum) mais altos. ${ }^{39}$

Os exemplos recém-expostos podem lançar dúvida sobre medidas de combate à exploração contratual que não se baseiem na lógica de consequência e suponham, portanto, que esse combate seja capaz de ocorrer por outro meio que não o de uma alteração de payoffs pela qual a recusa a explorar seja não apenas a alternativa socialmente desejável, mas também a melhor para agentes atentos exclusivamente ao seu próprio interesse. Afinal, mesmo que o comportamento nem sempre se conforme aos postulados da escolha racional e que, por isso, sejam regras, e não consequências, o que guie a tomada de certas decisões, trabalhos como o de Pillutla e Chen e Batson e Moran sugerem que a substituição da lógica da consequência pela da adequabilidade 
é menos propensa a ocorrer quando a decisão for percebida pelos agentes como dizendo respeito a uma transação comercial, o que é muito provavelmente o caso de decisões envolvendo as condições contratuais a oferecer a trabalhadores e consumidores.

Além disso, o estudo de Dijk e Wilke leva a crer que, ao representar, como é comum, a relação do empresário com os bens de produção como relação de propriedade individual, ajuda-se a constituir um frame decisório propício ao egoísmo. Por fim, o fato de a exploração - e, em especial, a exploração que aqui se tem particularmente em vista - ser determinante para a subsistência da empresa leva o contexto no qual a decisão sobre explorar ou não é tomada a mostrar-se como uma ato daqueles que exigem deliberação mais cuidadosa, outra das condições que Weber, Kopelman e Messick consideram propícias à lógica da consequência. ${ }^{40}$

Não é adequado, no entanto, entenderem-se as duas lógicas decisórias a que se tem feito alusão como lógicas excludentes, no sentido de que ou bem o agente se conduz de maneira a maximizar sua utilidade esperada e, portanto, com atenção unicamente para as consequências, ou faz uso de uma lógica da adequabilidade por força da qual essas consequências são completamente ignoradas, entrando, no lugar da sua ponderação, a sujeição pura e simples à norma de conduta que se julgue adequada para a situação. Ao contrário, é possível conceber-se o uso concomitante das duas lógicas decisórias e, portanto, descrever-se o processo decisório como capaz de oscilar entre dois polos - o das consequências e o das normas - ora se aproximando mais de um, ora do outro. ${ }^{41}$ Assim, o fato de as circunstâncias sob as quais decisões relativas à exploração contratual são tomadas favorece o predomínio da lógica da consequência e não impede que essas decisões sejam em alguma medida determinadas por normas e, como tais, deixem de corresponder exatamente ao que seria de esperar para indivíduos racionais e autointeressados.

Além disso, se o quadro da decisão sobre a exploração contratual sugere o uso de uma lógica da consequência, isso pode se dever também a normas sociais aplicadas à atividade empresarial e mostrar-se, por isso, manipulável à medida que essas normas também o sejam. Podese cogitar, em outras palavras, de uma outra relação entre as lógicas 
de decisão antes apresentadas como antagônicas, pela qual o uso da lógica da consequência seja, ele mesmo, resultado de um juízo ou "resposta" (caso se queira usar termo mais apropriado a decisões menos refletidas) de adequação. A decisão de maximizar a própria utilidade seria, segundo tal concepção, o resultado do reconhecimento, pelo agente, da situação em que se encontra como uma na qual é adequado comportar-se segundo a regra do autointeresse. Essa seleção da regra do autointeresse como regra a seguir pode ser determinada, tendo-se em conta a distinção entre normas sociais descritivas e injuntivas, ${ }^{42}$ tanto por aquilo que o agente observe ser comum para situações análogas àquela em que se encontra (normas descritivas), como pelo que considere ele próprio ser correto ou aprovado pelos demais para tal situação (normas injuntivas). Mesmo, portanto, que a situação na qual um contrato potencialmente exploratório se celebra se subsuma à situação prototípica de uma relação comercial, não é de descartar que um maior nível de cooperação (entendida como recusa à exploração) venha a ser alcançado mediante uma alteração da percepção dos agentes sobre o comportamento habitual nessas situações (isto é, mediante uma alteração das normas descritivas) ou pela internalização e disseminação de normas sociais (injuntivas) contrárias à maximização da utilidade. ${ }^{43}$

\section{SISTEMAS SANCIONADORES}

Sea cooperaçãoé difícil de obter devidoàs motivações egoístas dos agentes ou a um contexto decisório propenso a que essas motivações predominem, como é, plausivelmente, o da exploração contratual em mercados competitivos, a solução para uma situação de dilema pode ser, como antes observado, uma solução estrutural graças à qual se proporcione a agentes exclusivamente autointeressados o incentivo adequado a que atuem da maneira socialmente desejada. Entre as espécies de solução estrutural familiares à teoria dos dilemas, está a dos "sistemas sancionadores" (sanctioning systems), modo como se designam medidas de resposta à defecção destinadas a obter a cooperação por meio de um alinhamento dos interesses de cada um dos envolvidos ao interesse da coletividade. 
A aptidão de sistemas sancionadores para a superação de dilemas sociais pode ser entendida como um dos motivos para que a ciência do Direito tenha, até hoje, dispensado muito menos atenção a esses dilemas do que outras ciências afins. Afinal, exemplo por excelência de sistema sancionador é o sistema jurídico, capaz de obter, mediante coerção, a cooperação de agentes ocupados exclusivamente com o seu próprio bem-estar. A exploração contratual é apenas um entre incontáveis casos nos quais a busca de cada um pela própria satisfação é contida pela ameaça da sanção legal, que se manifesta, no que toca à exploração, como recusa a conferir validade e, em última instância, aplicação a contratos abusivos, bem como pela punição, administrativa e até criminal, dos que insistam em celebrá-los. À medida, pois, que o Direito consiga, mediante sanções, provocar o esfacelamento de dilemas sociais, poder-se-ia concluir que o estudo desses dilemas é mesmo mais adequado a disciplinas, como a Psicologia, a Economia e a Ciência Política, para as quais a existência de um sistema sancionador como o que é constituído pelas normas jurídicas não seja pressuposta.

A pesquisa sobre sistemas sancionadores em dilemas sociais não tem feito, no entanto, apenas confirmar o sucesso de sistemas sancionadores. Há, de um lado, estudos que atestam o efeito desejável de sanções, das quais resultariam maiores níveis de cooperação. ${ }^{44}$ Não faltam, por outro, trabalhos nos quais um efeito oposto é revelado. Farse-á, a seguir, um sumário.

Um dos possíveis inconvenientes de sistemas sancionadores é designado em Psicologia como efeito de superjustificação (overjustification effect). ${ }^{45}$ Parte-se da premissa de que certas atividades são desempenhadas por seu valor intrínseco. Uma vez, no entanto, que essas atividades comecem a ser recompensadas, a motivação dos agentes para exercê-las seria minada, de tal maneira que, ao cancelar-se, posteriormente, a premiação, o nível da atividade (outrora realizada sob motivação intrínseca, agora dependente de estímulo externo) cairia. Embora os trabalhos sobre o efeito de superjustificação refiram-se mais comumente a outros incentivos que não os criados por normas jurídicas sancionadoras, a possibilidade de que essas últimas produzam o referido efeito não tem por que ser desconsiderada. ${ }^{46}$ 
Outra suposição, também pessimista acerca das consequências de um sistema de sanções, relaciona-se com a teoria dos quadros decisórios. Tenbrunsel e Messick testaram com sucesso a hipótese de que um sistema sancionador brando redunde em níveis de cooperação inferiores aos da falta de sanções. ${ }^{47}$ Ao invés, no entanto, de sugerir que a sanção faça desaparecer a motivação intrínseca dos agentes a cooperar (um efeito que, dada a insignificância da sanção, não seria compensado pelo estímulo externo que dela advém), os autores atribuem o resultado a uma alteração no quadro decisório. Sob ameaça de sanção, alguns agentes passariam a perceber a decisão a tomar não mais como decisão ética, mas como uma decisão "comercial" a requerer um comportamento maximizador de utilidade.

Finalmente, Mulder e colegas cogitam sobre um possível efeito sinalizador das sanções. ${ }^{48}$ A cominação de uma sanção pode ser entendida por alguns indivíduos como sinal da indisposição a cooperar dos demais (já que, de outro modo, a sanção não se faria necessária). A falta de confiança nos pares, por sua vez, incitaria esses indivíduos a se conduzirem de maneira autointeressada, um resultado explicável tanto à luz do que se sabe a respeito da influência de normas descritivas (isto é, da tendência a repetir o comportamento dos demais) ${ }^{49}$ como à base da suposição, já confirmada, ${ }^{50}$ de que muitas pessoas são "cooperadoras condicionais", isto é, encontram-se inclinadas a cooperar apenas à medida que os demais também o façam. ${ }^{51}$

Mesmo, porém, que sistemas sancionadores, de que é exemplo o sistema jurídico, tenham o efeito indesejável que os trabalhos por último citados insinuam, nada assegura que a supressão das sanções uma vez estabelecidas conduza, ainda que a mais longo prazo, a uma melhora. A esse respeito, é importante salientar que o efeito superjustificatório aventado em trabalhos de Psicologia não desaparece imediatamente depois que os incentivos são retirados. Pelo contrário, é o cancelamento desses incentivos que torna manifesta, pela redução dos níveis de atividade, a influência deletéria do estímulo sobre a motivação intrínseca dos agentes. Isso é importante quando se trata, como no caso da exploração contratual no Brasil, de uma área a respeito da qual, consideradas as restrições já previstas na legislação, o debate sobre políticas públicas pode concernir tanto à criação de sanções 
como à eliminação delas. Embora as medidas atuais de combate a contratos exploratórios possam ter ajudado a vicejar o comportamento autointeressado (sobretudo entre contratantes habituais, como são os empresários), a revogação dessas medidas à presente altura poderia conduzir a um resultado ainda mais nefasto, ao tirar de cena o único fator (o estímulo externo, correspondente à ameaça de sanção) de entrave à exploração.

Caso se queira, portanto, procurar outras soluções para o dilema da exploração contratual que não a dita intervenção estatal por meio da proibição, pura e simples, de cláusulas abusivas nos contratos, medidas mais sofisticadas do que a supressão dos limites legais hoje em vigor devem ser cogitadas. Entre essas medidas, podem estar inovações quanto ao modo de legislar sobre a exploração contratual graças às quais, mesmo que se lance mão, ao fim e ao cabo, de normas sancionadoras, consiga-se prevenir ou atenuar o efeito negativo dessas últimas. Sugere-se, por exemplo, que medidas procedimentais pelas quais se aumente a participação dos envolvidos podem evitar o efeito superjustificatório de sanções. ${ }^{52}$ Isso se apoia na hipótese, aventada pela Psicologia, de que a perda de motivação intrínseca advinda de estímulos externos esteja relacionada com uma necessidade de autodeterminação que a atividade, uma vez recompensada, deixaria de satisfazer. ${ }^{53}$ Em consequência, quanto mais intensa for a participação dos agentes na criação de medidas destinadas a refrear a exploração, menos inibidoras da motivação intrínseca a cooperar talvez sejam essas medidas. Outra possível virtude da participação seria a de disseminar uma norma social antiexploratória, o que, como visto, é importante tanto para agentes egoístas que temam as sanções informais relacionadas com o descumprimento dessas normas, quanto para os casos de tomada de decisão sujeitos a uma lógica de adequabilidade. Mais ainda, a participação de potenciais agentes e vítimas em um debate sobre medidas de prevenção à exploração talvez impedisse tais medidas de servir como sinal da falta de disposição a cooperar. 


\section{CONSIDERAÇÕES FINAIS}

Depois de caracterizar a exploração contratual em mercados competitivos como dilema social, procurou-se, no presente artigo, aplicar-lhe parte da teoria relativa a esses dilemas. Situações de dilema social distinguem-se pelo fato de a atuação autointeressada dos envolvidos trazer consigo um resultado socialmente indesejável. À medida, pois, que a hipótese do autointeresse se confirme, a realização do bem coletivo (que se pressupôs aqui corresponder a uma sociedade livre de exploração) depende de uma intervenção (ou solução estrutural) por meio da qual os payoffs se alterem e a busca de cada indivíduo pela própria satisfação acabe, ao mesmo tempo, por servir ao bem comum. Uma das espécies de intervenção assim é a que ocorre por meio de normas jurídicas.

O que a literatura acerca dos dilemas sociais revela, no entanto, é que a hipótese de agentes exclusivamente autointeressados é, com frequência, desmentida. Mais ainda, essa mesma literatura reúne evidências de que, embora aptas a alcançar a cooperação mediante o estímulo que proporcionam, sanções como as estabelecidas pelo sistema legal podem ter um efeito deletério sobre a disposição a cooperar dos agentes, e isso seja pela informação que veiculam (já que a sanção pode ser entendida como sinal da falta de disposição a cooperar dos demais), seja pela perda de motivação intrínseca que o estímulo externo é capaz de desencadear. Se, por um lado, pois, a coerção jurídica mostra-se menos indispensável do que seria caso os agentes se dedicassem, de fato, apenas à maximização da própria utilidade, por outro, constatase que essa mesma coerção, uma vez instaurada, pode ser um entrave a que a cooperação ocorra "naturalmente", isto é, sem o incentivo de um sistema jurídico.

No caso da exploração contratual, viu-se que uma cooperação independente da ameaça proveniente de sanções legais é dificultada pelo fato de a identificação com o grupo, um dos fatores determinantes da cooperação, ter de se realizar não apenas entre os indivíduos (potenciais exploradores) cujo comportamento egoísta acarreta um resultado socialmente indesejável, mas também entre esses indivíduos e aqueles a quem a abolição da exploração mais de perto interessaria. Além disso, 
mesmo se admitindo que a decisão de cooperar se sujeite muitas vezes a uma lógica de adequabilidade antes do que a uma lógica de consequência (e que deixe, portanto, de apresentar-se como escolha racional, maximizadora de utilidade), o que se sabe a respeito dos correspondentes "desvios de racionalidade" leva a conclusões pouco otimistas acerca da exploração contratual. Assim, considerando-se as evidências de que o cálculo egoísta baseado nas consequências é mais frequentemente substituído pela obediência a uma norma adequada à situação quando a decisão a tomar for percebida como decisão "ética" do que como decisão comercial relacionada com o exercício da propriedade individual, chegase à conclusão de que os dados culturais relevantes para a exploração contratual de trabalhadores ou consumidores são pouco propícios à cooperação, e isso ainda que essa exploração se veja ocasionalmente limitada pela influência de normas sociais.

A pesquisa a respeito dos dilemas sociais sugere, não obstante, algumas alternativas ao combate à exploração contratual por meio de sanções. Embora discrepem da maneira habitual de coibir a exploração contratual (isto é, a da sanção correspondente à invalidação do contrato ou à punição dos agentes exploradores), essas alternativas interessam ao Direito. Mencione-se, a esse respeito, em primeiro lugar, a importância dos quadros decisórios e a possibilidade de que esses quadros sejam alterados também pela intervenção de normas jurídicas, embora não pela ameaça de sanção em si e sim pelo conteúdo expressivo dessas normas. ${ }^{54}$ Em segundo lugar, seria talvez útil dedicar mais atenção ao papel de entrave à exploração de normas sociais, e isso tanto sob o ponto de vista de agentes autointeressados para os quais a conformidade a essas normas tenha como exclusivo fim o de evitar as sanções informais que a violação faria recair sobre si, quanto, e sobretudo, para ocasiões em que a tomada de decisão seja determinada menos pelas consequências e mais pelo que o agente reconheça, mais ou menos conscientemente, ser o comportamento adequado para a situação. A relação entre o Direito e as normas sociais e, em particular, a possibilidade de essas últimas serem influenciadas pelo primeiro de maneira a se obter, por intermédio das referidas normas, resultados que as sanções legais seriam incapazes de realizar ou só capazes de realizar a um certo custo, é algo a ser cogitado em trabalhos futuros. 


\section{REFERÊNCIAS}

BALLIET, Daniel. Communication and cooperation in social dilemmas: a meta-analytic review. Journal of Conflict Resolution, v. 54, n. 1, p. 39-57, 2010.

BATSON, C. Daniel; MORAN, Tecia. Empathy-induced altruism in a prisoner's dilemma. European Journal of Social Psychology, v. 29, n. 7, p. 909-924, 1999.

BIEL, Anders; THØRGENSEN, John. Activation of social norms in social dilemmas: a review of the evidence and reflections on the implications for environmental behaviour. Journal of Economic Psychology, v. 28, p. 93-112, 2007.

CIALDINI, Robert B.; RENO, Raymond R.; KALLGREN, Carl R. A focus theory of normative conduct: recycling the concept of norms to reduce littering in public places. Journal of Personality and Social Psychology, v. 58 , n. 6, p. 1.015-1.026, 1990.

DAWES, Robyn M. Social dilemmas. Annual Review of Psychology, v. 31, p. 169-193, 1980.

DE CREMER, David; VAN VUGT, Mark. Social identification effects in social dilemmas: a transformation of motives. European Journal of Social Psychology, v. 29, p. 871-893, 1999.

DECI, Edward L. Effects of externally mediated rewards on intrinsic motivation. Journal of Personality and Social Psichology, v. 18, n. 1, p. 105115, 1971.

DECI, Edward L.; RYAN, Richard M. Intrinsic motivation and selfdetermination in human behavior. Nova Iorque: Plenum, 1985.

FISCHBACHER, Urs; GÄCHTER, Simon; FEHR, Ernst. Are people conditionally cooperative? Evidence from a public goods experiment. Economics Letters, v. 71, p. 397-404, 2001.

FREY, Bruno S. A constitution for knaves crowds out civic virtues. The Economic Journal, v. 107, n. 443, p. 1.043-1.053, 1997.

GÄCHTER, Simon. Conditional cooperation: behavioral regularities from the lab and the field and their policy implications. In: FREI, Bruno S.; STUTZER, Alois (Ed.). Economics and Psychology: a promising new cross-disciplinary field. Cambridge: MIT Press, 2007. p. 19-49. 
GINTIS, Herbert et al. Moral sentiments and material interests: origins, evidence, and consequences. In: GINTIS, Herbert et al. (Ed.). Moral sentiments and material interests: the foundations of cooperation in economic life. Cambridge: MIT Press, 2005. p. 3-40.

HANSON, Jon D.; KYSAR, Douglas D. Taking behavioralism seriously: the problem of market manipulation. New York University Law Review, v. 74, n. 3, p. 630-749, 1999.

HART, Herbert L. A. O conceito de direito. Tradução de Armindo Ribeiro Mendes. Lisboa: Calouste Gulbenkian, 1986.

ISAAC, R. Mark; WALKER, James M. Group size effects in public goods provision: the voluntary contributions mechanism. The Quarterly Journal of Economics, v. 103, n. 1, p. 179-199, 1988.

KAHNEMAN, Daniel; KNETSCH, Jack L.; THALER, Richard. Fairness as a constraint on profit seeking: entitlements in the market. The American Economic Review, v. 76, n. 4, p. 728-741, 1986.

KOLLOCK, Peter. Social dilemmas: the anatomy of cooperation. Annual Review of Sociology, v. 24, p. 183-214, 1998.

KRAMER, Roderick M.; BREWER, Marilyn B. Choice behavior in social dilemmas: effects of social identity, group size, and decision framing. Journal of Personality and Social Psychology, v. 50, n. 3, p. 543-549, 1986.

KRAMER, Roderick M.; GOLDMAN, Lisa. Helping the group or helping yourself? Social motives and group identity in resource dilemmas. In: SCHROEDER, David A. (Ed.). Social dilemmas: perspectives on individuals and groups. Westport: Praeger, 1995. p. 49-67.

LEPPER, Mark R.; GREENE, David; NISBETT, Richard E. Undermining children's intrinsic interest with extrinsic reward: a test of the "overjustification hypothesis". Journal of Personality and Social Psichology, v. 28, n. 1, p. 129137, 1973.

MARCH, James G. A primer on decision making: how decisions happen. Nova Iorque: The Free Press, 1994.

McADAMS, Richard H. The origin, development, and regulation of norms. Michigan Law Review, v. 96, p. 338-433, 1997. 
McADAMS, Richard H. Beyond the prisoner's dilemma: coordination, game theory, and law. Southern California Law Review, v. 82, n. 2, p. 209-258, 2009.

MULDER, Laetitia B. et al. Undermining trust and cooperation: the paradox of sanctioning systems in social dilemmas. Journal of Experimental Social Psychology, v. 42, p. 147-162, 2006.

NEGREIROS, Teresa. Teoria do contrato: novos paradigmas. 2. ed. Rio de Janeiro: Renovar, 2006.

NORONHA, Fernando. O direito dos contratos e seus princípios fundamentais: autonomia privada, boa-fé, justiça contratual. São Paulo: Saraiva, 1994.

PILLUTLA, Madan M.; CHEN, Xiao-Ping. Social norms and cooperation in social dilemmas: the effects of context and feedback. Organizational Behavior and Human Decision Processes, v. 78, n. 2, p. 81-103, 1999.

POSNER, Eric A. 2000. Law and social norms. Cambridge: Harvard University Press, 2000.

SCHROEDER, David A. An introduction to social dilemmas. In: SCHROEDER, David A. (Ed.). Social dilemmas: perspectives on individuals and groups. Westport: Praeger, 1995. p. 1-14.

SHINADA, Misuho; YAMAGISHI, Toshio. Bringing back Leviathan into social dilemmas. In: BIEL, Anders et al. (Ed.). New issues and paradigms in research on social dilemmas. Nova Iorque: Springer, 2008. p. 93-123.

SUNSTEIN, Cass. On the expressive function of law. University of Pennsylvania Law Review, v. 144, p. 2.021-2.053, 1996.

TENBRUNSEL, Ann E.; MESSICK, David M. Sanctioning systems, decision frames, and cooperation. Administrative Science Quarterly, v. 44, p. 684707, 1999.

TVERSKY, Amos; KAHNEMAN, Daniel. The framing of decisions and the psychology of choice. Science, v. 211, n. 4.481, p. 453-458, 1981.

VAN DIJK, Eric; WILKE, Henk. Is it mine or is it yours? Framing property rights and decision making in social dilemmas. Organizational Behavior and Human Decision Processes, v. 71, n. 2, p. 195-209, 1997. 
VAN LANGE, Paul A. M. Rationality and morality in social dilemmas: the influence of social value orientations. In: LIEBRAND, Wim; MESSICK, David; WILKE, Henk (Ed.). Social dilemmas: theoretical issues and research findings. Oxford: Pergamon Press, 1992. p. 133-146.

WEBER,J.Mark; KOPELMAN,Shirli;MESSICK, David M. A conceptual review of decision making in social dilemmas: applying a logic of appropriateness. Personality and Social Psychology Review, v. 8, n. 3, p. 281-307, 2004.

WERTHEIMER, Alan. Exploitation. Princeton: Princeton University Press, 1996.

ZANITELLI, Leandro Martins. A reciprocidade nos contratos: uma análise expressivista. Revista de Direito Privado, São Paulo, v. 42, p. 160-184, 2010.

ZANITELLI, Leandro Martins. Efeito de superjustificação e intervenção legal nos contratos. Inédito.

\section{NOTAS}

1 NORONHA, Fernando. O Direito dos contratos e seus princípios fundamentais: autonomia privada, boa-fé, justiça contratual. São Paulo: Saraiva, 1994. p. 205-249.

2 NEGREIROS, Teresa. Teoria do contrato: novos paradigmas. 2. ed. Rio de Janeiro: Renovar, 2006. p. 156-206.

3 V., p. ex., TJRS, AC n 70024053944 (função social do contrato como limite ao aumento do prêmio por faixa etária em contrato de seguro de vida).

$4 \quad$ V., p. ex., STJ, REsp. n 735.168/RJ (nulidade, por contrariedade à boa-fé, de cláusula de contrato de plano de saúde que excluía cobertura para despesas com o "stent" a ser usado em cirurgia cardíaca).

5 WERTHEIMER, Alan. Exploitation. Princeton: Princeton University Press, 1996. p. 217-218, tradução nossa. No original: "I do not want to deny that exploitation can occur in a perfectly competitive market [...]. Nonetheless, when we say that A takes unfair advantage of B, we typically assume that A could have chosen not to take unfair advantage of $\mathrm{B}$, that their transaction could have occurred on fairer terms. And this is precisely what generally cannot occur in a perfectly competitive market. [...] If an employer pays his employees too much, he will be driven out of business by competitors who can undersell him because they are paying less to their employees". 
6 Segundo Wertheimer, (1996, p. 217), poder-se-ia, isso sim, submeter a um juízo moral a decisão de tornar-se empresário.

7 DAWES, Robyn M. Social dilemmas. Annual Review of Psychology, v. 31, p. 169-193, 1980, p. 169.

8 Note-se, por exemplo, o que dizem Weber, Kopelman e Messick sobre o interesse despertado pelos dilemas sociais em diferentes áreas do conhecimento (WEBER, J. Mark; KOPELMAN, Shirli; MESSICK, David M. A conceptual review of decision making in social dilemmas: applying a logic of appropriateness. Personality and Social Psychology Review, v. 8, n. 3, p. 281-307, 2004, p. 281-282, tradução nossa):

Psicólogos sociais, antropólogos, economistas, sociólogos e cientistas políticos têm igualmente demonstrado grande interesse em entender sob que condições indivíduos fazem escolhas cooperativas ao invés de egoístas, por que eles fazem essas escolhas e que espécies de intervenção são capazes de obter um comportamento socialmente mais vantajoso (no original: "Social psychologists, anthropologists, economists, sociologists and political scientists alike have demonstrated great interest in understanding when people make cooperative choices rather than selfish choices, why people make the choices they do, and the kinds of interventions that are effective in eliciting more socially advantageous behavior).

A não inclusão do Direito no rol de áreas com tradição no estudo de dilemas sociais, surpreendente quando se considera a frequência e diversidade de áreas, muitas delas sujeitas à regulação jurídica, com que esses dilemas se apresentam, não deve ser atribuída a mero lapso dos autores. Para afirmação similar a recém-reproduzida, v. SCHROEDER, David A. An introduction to social dilemmas. In: SCHROEDER, David A. (Ed.). Social dilemmas: perspectives on individuals and groups. Westport: Praeger, 1995. p. 1-14, p. 1.

A falta de atenção à teoria dos dilemas sociais em estudos jurídicos é mais pronunciada no Brasil do que em outros lugares. Para um relato sobre o uso do dilema do prisioneiro, o exemplo mais comum de dilema social, em trabalhos jurídicos de língua inglesa, v. McADAMS, Richard H. Beyond the prisoner's dilemma: coordination, game theory, and law. Southern California Law Review, v. 82, n. 2, p. 209-258, 2009, p. 214.

9 DAWES, op. cit., p. 169.

10 KOLLOCK, Peter. Social dilemmas: the anatomy of cooperation. Annual Review of Sociology, v. 24, p. 183-214, 1998, p. 183, tradução nossa. No original: "Social dilemmas are situations in which individual rationality leads to collective irrationality". 
11 Embora apresente as propriedades de um dilema social, o dilema do prisioneiro é um dilema de duas pessoas, diferenciando-se dos casos em que, como no exemplo dos dejetos do cão anteriormente referido, o número de envolvidos é bem maior (dilema de múltiplas pessoas ou dilema de n-pessoa, n-person dilemma). Ocorre, por isso, de reservar-se a expressão "dilema social" para as ocasiões em que, diferentemente do que se dá na versão tradicional, reproduzida no texto, do dilema do prisioneiro, o número de protagonistas é maior (v. SCHROEDER, op. cit., p. 7-8). Embora o número de agentes seja, sem dúvida, relevante, emprega-se acima a expressão "dilema social" para qualquer situação que possua as características salientadas por Dawes (loc. cit.), independentemente da quantidade de envolvidos. Para um exemplo de uso da expressão nessa acepção mais ampla, v. KOLLOCK, Social dilemmas, op. cit., p. 188.

12 Isso é verdadeiro para um mercado perfeitamente competitivo, no qual a taxa de lucro tende ao zero. Em mercados imperfeitos, a oferta de salários superiores aos da concorrência pode não impedir que os preços dos produtos de $X$ se igualem aos demais, caso no qual a consequência para o empresário que escolha pagar s1 é a de ter de se contentar com um lucro menor. Mesmo em tal hipótese, contudo, pagar s0 manter-se-ia como estratégia dominante para $X$ e seus competidores.

13 HANSON, Jon D.; KYSAR, Douglas D. Taking behavioralism seriously: the problem of market manipulation. New York University Law Review, v. 74, n. 3, p. 630-749, 1999, p. 726.

14 DAWES, Social dilemmas, op. cit., p. 169.

15 Para um sumário, v. GINTIS, Herbert et al. Moral sentiments and material interests: origins, evidence, and consequences. In: GINTIS, Herbert et al. (Ed.). Moral sentiments and material interests: the foundations of cooperation in economic life. Cambridge: MIT Press, 2005. p. 3-40.

16 V. VAN LANGE, Paul A. M. Rationality and morality in social dilemmas: the influence of social value orientations. In: LIEBRAND, Wim; MESSICK, David; WILKE, Henk (Ed.). Social dilemmas: theoretical issues and research findings. Oxford: Pergamon Press, 1992. p. 133-146.

17 V., p. ex., SHINADA, Misuho; YAMAGISHI, Toshio. Bringing back Leviathan into social dilemmas. In: BIEL, Anders et al. (Ed.). New issues and paradigms in research on social dilemmas. Nova Iorque: Springer, 2008. p. 93-123, p. 95. 
18 V., p. ex., KRAMER, Roderick M.; BREWER, Marilyn B. Choice behavior in social dilemmas: effects of social identity, group size, and decision framing. Journal of Personality and Social Psychology, v. 50, n. 3, p. 543-549, 1986.

19 Para o que segue, v. KRAMER, Roderick M.; GOLDMAN, Lisa. Helping the group or helping yourself? Social motives and group identity in resource dilemmas. In: SCHROEDER, David A. (Ed.). Social dilemmas: perspectives on individuals and groups. Westport: Praeger, 1995. p. 4967, p. 56. V. também DE CREMER, David; VAN VUGT, Mark. Social identification effects in social dilemmas: a transformation of motives. European Journal of Social Psychology, v. 29, p. 871-893, 1999, p. 872873 e referências lá contidas.

20 Para um experimento demonstrando a importância da variável tamanho do grupo para a cooperação, v. KRAMER; BREWER, Marilyn B. Choice behavior in social dilemmas, op. cit. Em outro estudo, Isaac e Walker confirmaram a influência do grau de eficácia (ou retorno marginal) das contribuições individuais para o nível de cooperação, mas não do tamanho do grupo em si mesmo. V. ISAAC, R. Mark; WALKER, James M. Group size effects in public goods provision: the voluntary contributions mechanism. The Quarterly Journal of Economics, v. 103, n. 1, p. 179199, 1988.

21 WEBER; KOPELMAN; MESSICK. A conceptual review of decision making in social dilemmas, 2004.

$22 \mathrm{MARCH}$, James G. A primer on decision making: how decisions happen. Nova Iorque: The Free Press, 1994. p. 58.

23 Ibid., p. 2.

24 Ibid., p. 58.

25 WEBER; KOPELMAN; MESSICK, A conceptual review of decision making in social dilemmas, op. cit., p. 284.

26 Ibid., p. 284.

27 V. BALLIET, Daniel. Communication and cooperation in social dilemmas: a meta-analytic review. Journal of Conflict Resolution, v. 54, n. 1, p. 39-57, 2010.

28 WEBER; KOPELMAN; MESSICK. Op. cit., p. 297.

29 Ibid., p. 297. 
30 Sobre a ideia de aceitação de uma regra, v. HART, Herbert L. A. O conceito de direito. Tradução de Armindo Ribeiro Mendes. Lisboa: Calouste Gulbenkian, 1986. p. 92-101.

31 Um exemplo é a análise econômica das normas sociais. V. McADAMS, Richard H. The origin, development, and regulation of norms. Michigan Law Review, v. 96, p. 338-433, 1997; POSNER, Eric A. 2000. Law and social norms. Cambridge: Harvard University Press, 2000.

32 V., p. ex., BIEL, Anders; THØRGENSEN, John. Activation of social norms in social dilemmas: a review of the evidence and reflections on the implications for environmental behaviour. Journal of Economic Psychology, v. 28, p. 93-112, 2007.

33 WEBER; KOPELMAN; MESSICK. Op. cit., p. 284.

34 V. TVERSKY, Amos; KAHNEMAN, Daniel. The framing of decisions and the psychology of choice. Science, v. 211, n. 4.481, p. 453-458, 1981, p. 453.

35 Ibid., p. 453.

36 Para outras referências, v. WEBER, KOPELMAN; MESSICK. Op. cit., p. 299-301.

37 PILLUTLA, Madan M.; CHEN, Xiao-Ping. Social norms and cooperation in social dilemmas: the effects of context and feedback. Organizational Behavior and Human Decision Processes, v. 78, n. 2, p. 81-103, 1999.

38 BATSON, C. Daniel; MORAN, Tecia. Empathy-induced altruism in a prisoner's dilemma. European Journal of Social Psychology, v. 29, n. 7, p. 909-924, 1999.

39 VAN DIJK, Eric; WILKE, Henk. Is it mine or is it yours? Framing property rights and decision making in social dilemmas. Organizational Behavior and Human Decision Processes, v. 71, n. 2, p. 195-209, 1997.

40 WEBER; KOPELMAN; MESSICK. Op. cit., p. 284.

41 Embora o trabalho de WEBER, KOPELMAN; MESSICK. Op. cit., não se manifeste em favor de tal interpretação, ele tampouco a descarta.

42 V., p. ex., CIALDINI, Robert B.; RENO, Raymond R.; KALLGREN, Carl R. A focus theory of normative conduct: recycling the concept of norms to reduce littering in public places. Journal of Personality and Social Psychology, v. 58, n. 6, p. 1.015-1.026, 1990, p. 1.015. 
43 Sobre o papel de entrave à maximização de utilidade em mercados exercido por normas sociais de equanimidade (fairness), v. KAHNEMAN, Daniel; KNETSCH, Jack L.; THALER, Richard. Fairness as a constraint on profit seeking: entitlements in the market. The American Economic Review, v. 76, n. 4, p. 728-741, 1986). Escrevi sobre a importância de normas jurídicas que expressem aversão à exploração contratual para o surgimento e preservação de normas sociais antiexploratórias em ZANITELLI, Leandro Martins. A reciprocidade nos contratos: uma análise expressivista. Revista de Direito Privado, v. 42, p. 160-184, 2010, p. 174-178.

44 Para uma síntese, v. KOLLOCK. Op. cit., p. 204-206.

45 V. DECI, Edward L. Effects of externally mediated rewards on intrinsic motivation. Journal of Personality and Social Psichology, v. 18, n. 1, p. 105-115, 1971; LEPPER, Mark R.; GREENE, David; NISBETT, Richard E. Undermining children's intrinsic interest with extrinsic reward: a test of the "overjustification hypothesis". Journal of Personality and Social Psichology, v. 28, n. 1, p. 129-137, 1973.

46 Para uma análise sobre as implicações da hipótese do efeito de superjustificação para o Direito, v. FREY, Bruno S. A constitution for knaves crowds out civic virtues. The Economic Journal, v. 107, n. 443, p. 1.043$1.053,1997$. Tratei da importância do efeito de superjustificação para o Direito contratual em um estudo inédito, ZANITELLI, Leandro Martins. Efeito de superjustificação e intervenção legal nos contratos.

47 TENBRUNSEL, Ann E.; MESSICK, David M. Sanctioning systems, decision frames, and cooperation. Administrative Science Quarterly, v. 44, p. 684-707, 1999.

48 MULDER, Laetitia B. et al. Undermining trust and cooperation: the paradox of sanctioning systems in social dilemmas. Journal of Experimental Social Psychology, v. 42, p. 147-162, 2006.

49 CIALDINI; RENO; KALLGREN. Op. cit., p. 1.015.

50 V. FISCHBACHER, Urs; GÄCHTER, Simon; FEHR, Ernst. Are people conditionally cooperative? Evidence from a public goods experiment. Economics Letters, v. 71, p. 397-404, 2001.

51 GÄCHTER, Simon. Conditional cooperation: behavioral regularities from the lab and the field and their policy implications. In: FREI, Bruno S.; STUTZER, Alois (Ed.). Economics and Psychology: a promising new cross-disciplinary field. Cambridge: MIT Press, 2007. p. 19-49, p. 43. 
52 FREY. Op. cit., p. 1.046

53 DECI, Edward L.; RYAN, Richard M. Intrinsic motivation and self-determination in human behavior. Nova Iorque: Plenum, 1985. p. 62.

54 V., a respeito, SUNSTEIN, Cass. On the expressive function of law. University of Pennsylvania Law Review, v. 144, p. 2.021-2.053, 1996.

Artigo recebido em: 06/12/2010

Aprovado para publicação em: 21/12/2010 